\title{
STUDIES ON PUBERTY. PART I
}

\author{
BY \\ HAMILTON HOGBEN, J. A. H. WATERHOUSE, and LANCELOT HOGBEN
}

\section{INTRODUCTION}

Existing literature concerning the onset of human sexual maturity is more extensive with respect to the female than to the male. This is not surprising, in so far as the menarche is an event more abrupt than any change characteristic of puberty in the male, and one with more far-reaching social consequences. Whilst there is no shortage of recorded data with respect to the menarche, their value is by no means uniform. Many published enquiries admittedly refer to statements about its onset communicated by subjects concerned after a more or less protracted interval, with or without ancillary confirmation from other sources (for example, the mother). To this category belong, inter alia, such accounts as those of Barker and Stone (1936), Bersamin and Gonzales-Bersamin (1940), Boas (1932), Ito (1942), Kark (1943), Kennedy (1933), Michelson (1944), Mills (1941 a and b), Mills and Chenoweth (1938), Simmons and Greulich .(1943), Stone and Barker (1937). Other authors either fail to state explicitly whether they took any steps to verify the asserted date of occurrence of the event, or are insufficiently explicit about the type of verification they sought. Among such we may mention Borruat (1941), Gómez (1942), and Pryor (1936). Aside from uncertainties arising from undue reliance on personal testimony in contradistinction to direct observation, many published accounts are of limited usefulness owing to the nature of the sample selected for the purpose. For instance, some refer to experience of patients at clinics or in hospitals. Among the very few authors who have studied a more truly representative population sample and have recorded only the results of direct observation, in contradistinction to assertions made by the subjects themselves, are Bayer (1940) and Engle and Shelesnyak (1934).

Of all the literature we have had access to, none dealing with the menarche makes available a continuous picture of concomitant physical changes, such as enlargement of the breasts and proliferation of pubic or axillary hair; but several authors have attempted to relate onset of menstruation to skeletal changes of adolescence or to anthropometric measurements. Among such are Barker and Stone (1936), Bayer (1940), Boas (1932), Ito (1942), Michelson (1944), Pryor (1936), Simmons and Greulich (1943), and Stone and Barker (1937). More recently Shock (1941-46) has recorded agechanges and sex differences in adolescence with respect to blood pressure, pulse rate, basal metabolic rate, alveolar carbon dioxide tension, and excretion of sex hormones. Curiously enough, there has been little attention to such metrical indices as more especially signalize sexual dimorphism, for example shoulder and pelvic width, neck girth, etc. Recent papers by Borruat (1941) and by Schonfeld (1943) on, pubescence sufficiently emphasize how defective is our knowledge concerning sequence and duration of the several manifestations accompanying maturation of the male gonads. Most of the literature dealing with the male at present available is indeed of very doubtful scientific value by the very nature of the methods on which it relies. A noteworthy exception is a substantial contribution by Ellis (1946). For neither sex can we turn to accessible information which discloses a panoramic picture of sexual maturation exhibiting changes of form and function during the period between childhood and the attainment of maturity on a chronological time scale. Such a complete survey of the process of sexual maturation should show the order in which the changes take place, the duration of each phase, and the range of normal variability, as well as the inter-relationships of the different phases.

Several authors have discussed variation with respect to onset of puberty vis-à-vis extrinsic and intrinsic agencies; but a satisfactory analysis of the relevant variables, genetic, climatic, nutritional, or other, calls for more searching investigation of the sequence of phenomena and the variability to which they are subject in a fairly homogeneous population than information at present available in the literature of the subject can supply. There appears to be a widespread belief that considerable differences with regard to the time of onset of puberty separate stocks of different ethnic origin, but available 
records referring to different ethnic stocks domiciled under comparable climatic conditions do not disclose spectacular or even significant discrepancies. Authors such as Kennedy (1933), Klineberg (1935), Fluhmann (1936), and others who have reviewed the literature available concur in recognizing that such differences are dubious, or at best, small. Michelson (1944) has published data .about the menarche in several sample populations of both whites and negroes, including in all about 7,000 subjects. For different samples of whites, the age means extended over the range 13.08 to 13.62 years. For different samples of negroes, they extended from 13.35 to 13.99. When we give due weight to the uncertainty arising from undue reliance on the memory of the individual subject, we can hardly place great confidence in the conclusion that menarche of negroes is later than it is in whites. In any case, Michelson found no significant difference between such samples as were comparable with regard to socio-economic status and age at the time of questioning. In view of the highly dubious and at least trivial nature of differences attributable to ethnic origin, as such, we might expect to find a greater unanimity of testimony with regard to effects of climate. Contrary to the view commonly expressed in medical textbooks, writers who have lately reviewed the subject incline to the conclusion that hot climates delay the menarche.

In this connexion we may mention the writings of Kennedy (1933), Mills and Chenoweth (1938), Howe (1939), Ito (1942), Mills (1937, 1941 a, b, 1944), Kark (1943), Bersamin and GonzalesBersamin (1940), and Kark (1943). These authors concur in the definite assertion that menarche occurs later in the tropics than in temperate regions. Whilst their data are open to criticism on grounds stated above, they are at least as reliable as any cited to sustain the earlier and still prevalent belief that a warm environment favours early sexual maturity of the human female. The issue is one which clearly invites further enquiry, and it is regrettable that there are no statistically plausible data with respect to the male subject.

Attempts to probe the role of nature and nurture by comparisons between the age at menarche of mothers and daughters and the age at menarche of sisters, as by Bolk (1923) and by Gould and Gould (1932) are suggestive but inconclusive, if only because they rely on personal testimony of an event long after its occurrence. For the same reason, we may dismiss a copious literature by Mills (1937-44) and others attesting to a supposedly secular change of the date of menarche putatively associated with change of the social or physical environment. It is not unlikely that the alleged secular trend signifies nothing more than a systematic error of memorization. Authors who have investigated age at menarche in different social classes incline to the view that girls of the more prosperous sections of the community develop earlier. Among those who have directed attention to this class of variables are: Bersamin and Gonzales-Bersamin (1940), Fluhmann (1936), Kark (1943), Kennedy (1933), and Klineberg (1935), among other authors.

Authors who have made concomitant anthropometric observations have drawn attention to one or other of the following general conclusions:

(i) there is a rapid growth period in the six months before onset of menstruation;

(ii) the gain in height at this time precedes gain in weight;

(iii) women with later menarche continue to increase in weight and height more rapidly than early pubescents;

(iv) women who menstruate later therefore grow for a longer period, become taller and tend $\vec{\theta}$ to the leptosomate build, while those who

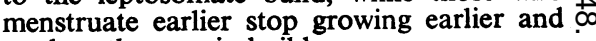
tend to the pycnic build.

There is little basis for comparison between the sequence of some of the most characteristic signposts of puberty in man and the course of sexual maturation in man's nearest allies. The delayed and $\stackrel{\mathbb{2}}{2}$ highly localized appearance of copious hair other $\overrightarrow{\overrightarrow{0}}$ than that of the scalp is highly characteristic of man 3 himself, as the localized alopoecia and coloration of the buttocks is highly characteristic of the? catarrhines. Yerkes (1943) cites the following figures for the approximate age range of pubescence $\frac{\rho}{?}$ (both sexes):

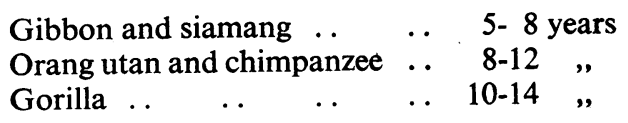

These figures suggest no sharp break between the $\frac{D}{0}$ apes and man. Information with respect to the gorilla is fragmentary, but Yerkes asserts that the $N$ female gorilla does not mature until over seven $N$ years. Since menarche of the human female may occur before nine years of age, we may infer that $\omega$ the dates of sexual maturation in the two species? overlap appreciably. In Yerkes' laboratory, chim - 은 panzees matured at seven to ten years, earlier than in records referable to more natural conditions.? Zuckerman's observations (1932) on the course of pubescence with special reference to the sexual skind of the chimpanzee show that it is protracted, $\frac{?}{\mathbb{C}}$ lasting about two years. As regards monkeys, 0 Hartman (1931) dates the beginning of menstruation 
of the rhesus macaque at four years. Yerkes gives the same age for the Chacma baboon, but Zuckerman had reported on a male Hamadryas still immature after four and a half years' captivity. Dr. Peter Eckstein (private communication) informs us that the onset of menarche in rhesus monkeys of known age in his experience is between $2 \frac{1}{4}$ and 3 years.*

\section{SCOPE OF ENQUIRY}

The immediate object of the present enquiry is: (a) to provide a picture of the sequence of changes associated with puberty in both sexes, with special reference to sexual dimorphism; (b) to examine variability with reference to both the onset and the duration of each phase in a relatively homogeneous population sample. It relies exclusively on direct observations of the subjects by a medically qualified investigator in the course of routine medical inspection of schoolchildren. $\dagger$

The ideal method of securing information of this kind would involve follow-up of each individual over a period including
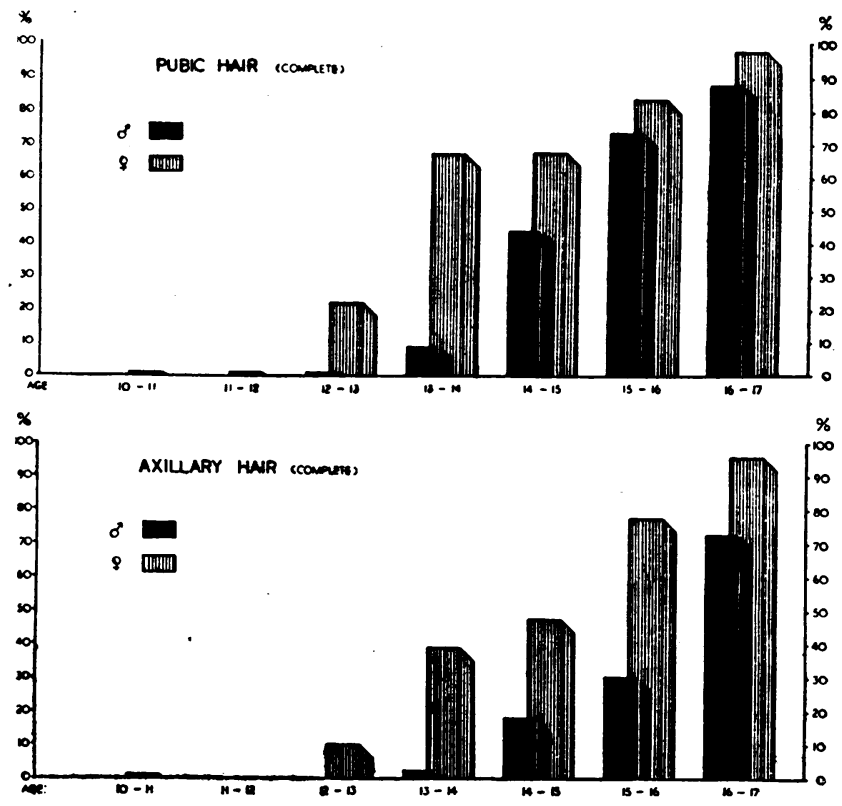

FIG. 1.-Representation of cumulative percentages of children in successive age groups with full development of pubic and axillary hair. Boys (black) superimposed on girls.

the beginning and the completion of the period of sexual development; but this procedure would necessitate a very protracted enquiry beset by many practical difficulties, unless based on small samples as in Shock's enquiries cited above. Accordingly, we have adopted an alternative plan, viz. that of recording the level of development reached by each child in a sample taken from each of a sequence of half-yearly age groups starting at eight and a half years. By this means, it is possible to assess (a) what proportion of individuals in a given age group have already reached a level defined by the presence or absence of a particular attribute of sexual maturation; (b) for each such age group the mean value of any metrical index relevant to morphogenetic divergence during sexual maturation.

The size of the sample examined was 900 girls and 850 boys,' but the numbers of records which were wholly satisfactory were respectively 662 and 642. Children of the older age groups attended one or other of the secondary (grammar) schools in the Borough of Tottenham; children of the lower

* Since writing the above, the authors have received the Edinburgh Medical Journal, vol. 54, June, 1947, containing a useful contribution by $\mathbf{R}$.W. B. Ellis, with the title "Growth in Relation to Maturity."

+ We acknowledge our great indebtedness to the Education Committee of the Borough of Tottenham, and to its Education Officer, to the Principals of the Schools in which examinations took place, to Dr. Norah Webster of the Public Health Department of the Borough, for collaboration in examining the children, to $\mathbf{M r}$. $\mathbf{R}$ Cawley for invaluable assistance in sorting the data, and to Miss Gladys Haines for preparation of charts.

age group attended primary schools of the borough under the same authority. The selected borough is itself a relatively homogeneous community with respect to socio-economic level, and the investigators used personal knowledge of the local set-up to draw on local primary schools providing instruction for children of families at a socio-economic level most nearly comparable to that of families from which the secondary schools themselves recruit their personnel.

The ultimate aim of the investigation takes within its scope an issue of wider interest than stated above. Design of the records provided for collecting: (a) information concerning school progress, health and social habits of the children; $(b)$ anthropometric data which may later provide the basis of a typological prognosis of early or late sexual development. At this stage, however, our concern is solely with the issue stated above. To that end the record of every child examined cited its age and sex grading with respect to certain qualitative attributes as specified below, and measurements to clarify such sexual dimorphism as dates especially from pubescence. It is a matter of common observation that the hips of the adult female are relatively wider than those of the adult male, and that the neck of the adult male is relatively thicker than that of the female before the menopause. We have concentrated our attention on this 
1

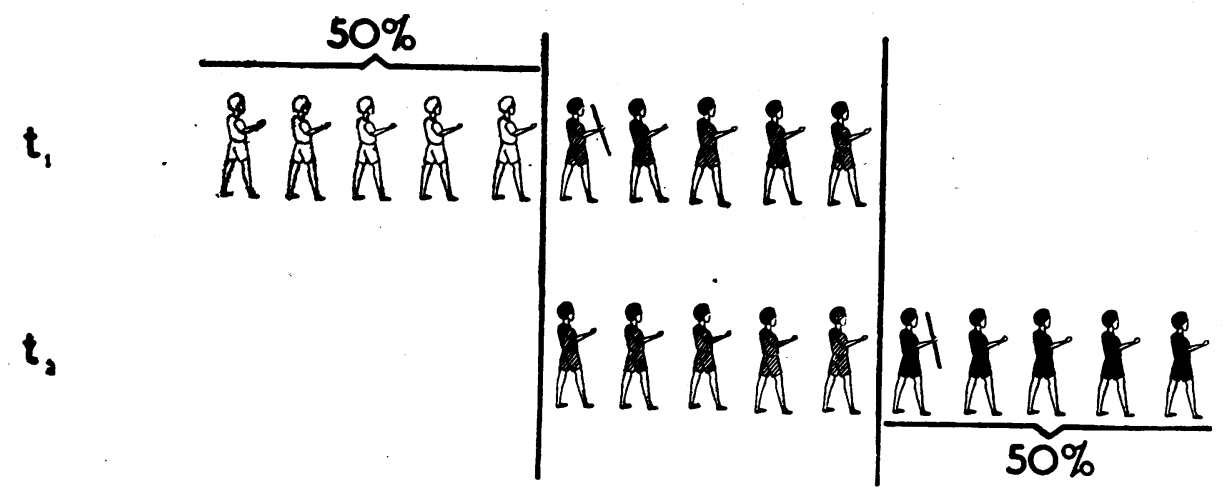

NOT YET STARTED

INCIPIENT

COMPLETE

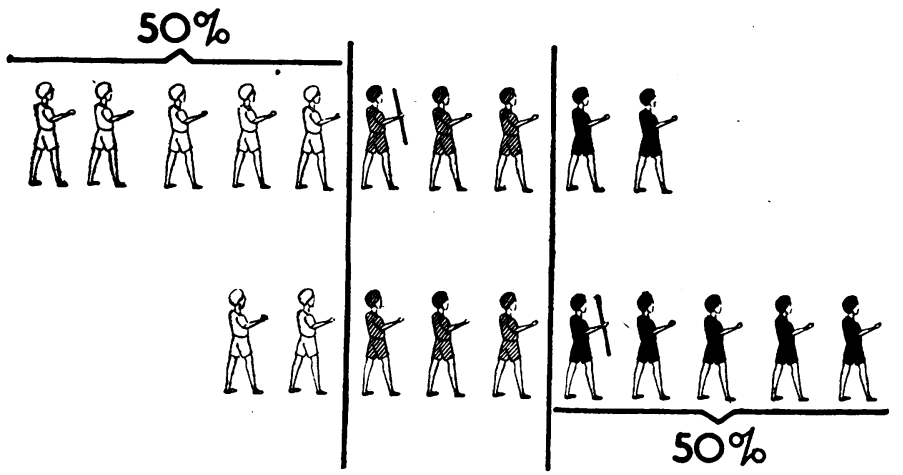

FIG. 2.-Diagrammatic representation of mean duration of development of characters amenable to specification by threefold split.

dimorphism, using as background data height, weight, trunk length, and shoulder (bisacromial) width. The qualitative attributes recorded by grades were as follows:

Hair-growth:
(a) pubic
absent
(b) axillary
absent
short
(c) chin
absent
(d) upper lip
absent
short
short
copious
copious
copious
short copious

Contour of pubic hair:

apical intermediate horizontal

Breasts:

(a) rudimentary enlarging full

(b) nipple retracted nipple normal

Menstruation:
(a) already
(b) regular
not yet
irregular

Testes:

retractile $\cdot$ non-retractile

Voice:

unbroken
Prepuce:

removed incomplete complete

Seminal activity:

$$
\text { already }
$$

not yet

Urine:

$$
\text { with albumin without albumin }
$$

It will suffice to say that reliable records of the penultimate item proved to be unobtainable and the exigencies of school routine limited opportunities for getting a sufficient sample of the last. In addition to items mentioned, and to a variety of other anthropometric data not relevant to the subject rnatter of this communication, the records covered included various qualitative attributes, e.g. eye and hair colour, other than those which distinguish the sexes. The main issues with which we are here concerned are:

(1) the mean age, and its variance at the appearance of each of the following characteristics: pubic hair, axillary hair, enlargement of 
breasts, retention of the testes in the scrotum, enlargement of the larynx, appearance of hair on chin and upper lip;

(2) the duration of the changes involved in the appearance of the characteristics above mentioned;

(3) delimitation of the date of the menarche;

(4) differentiation of pubic hair contour;

(5) differentiation of hip width and neck growth.

For the purpose of specifying date of closure of the inguinal canal, the procedure was as follows: On failure of the boy to accomplish voluntary retraction into the inguinal canal in the prone position, the examiner ascertained by gentle palpation in turn if either testis could be made to pass through the external abdominal ring. It is of minor interest to record in this context some information with reference to the condition of the prepuce among the boys. For the purposes of the ensuing three-fold split, "removed " signifies that circumcision had been carried out. Incomplete signifies that the foreskin did not extend to the top of the glans in its normal condition.

$$
\begin{array}{lllr}
\text { Removed } & \ldots & \ldots & 26 \cdot 4 \pm 1 \cdot 8 \\
\text { Incomplete } & \ldots & \ldots & 8 \cdot 1 \pm 1 \cdot 1 \\
\text { Complete } & \ldots & \ldots & 65 \cdot 5 \pm 1 \cdot 9
\end{array}
$$

\section{Computation of Age Distributions}

The raw data of this enquiry supply us with the means of plotting graphs which exhibit the incidence of a given attribute of sexual development in equally-spaced intervals of time. In a graph or histogram so constructed, age is in effect the independent variable with respect to which $y$, the percentage exhibition of the individual character, is the dependent one. To assess the course of events, either in terms of median age, or for the purpose of estimating the duration of the process of sexual

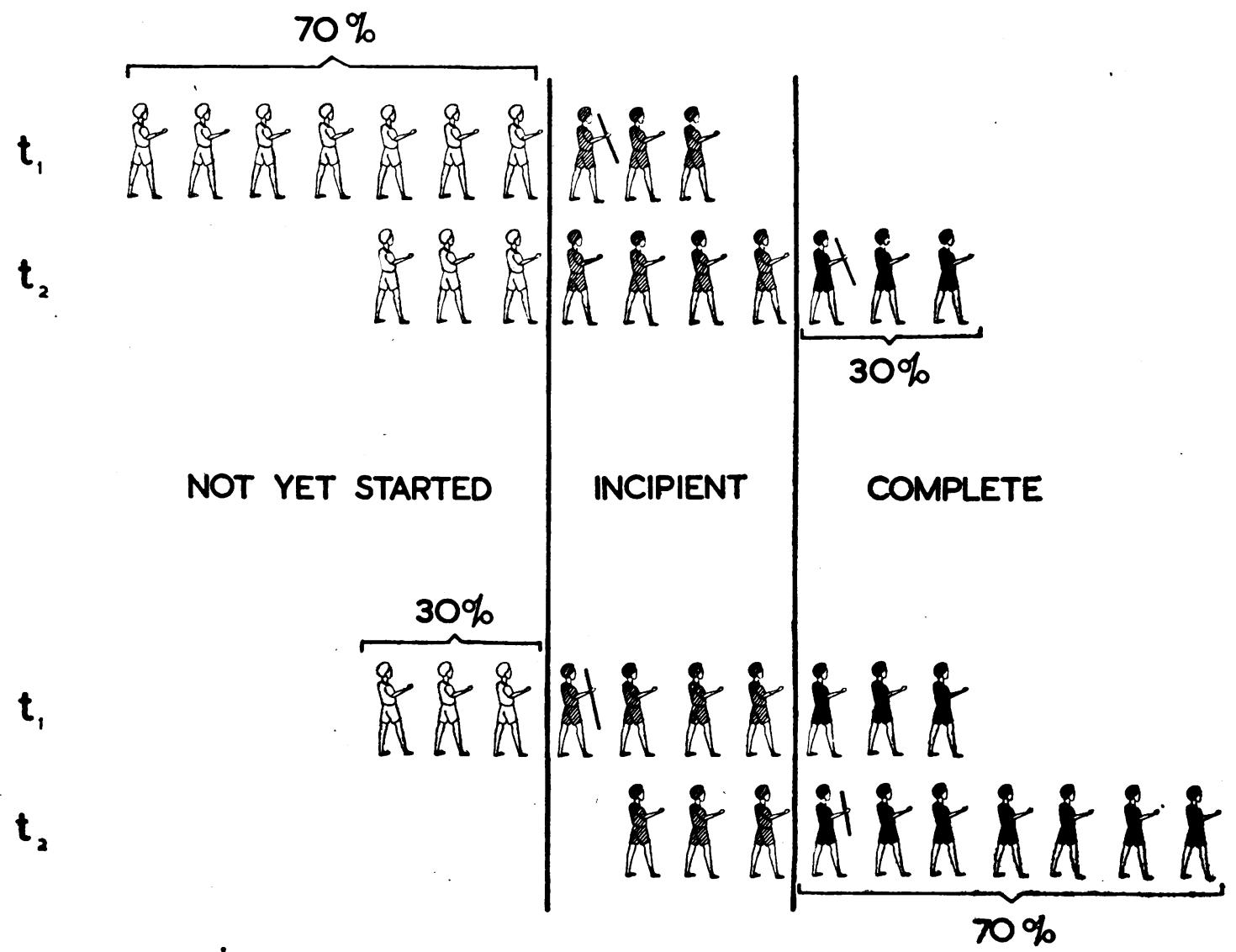

FIG. 3.-Diagrammatic representation of mean duration of development of characters amenable to specification by threefold split. 
differentiation, what we need to know is at what age any given proportion of the population sample has attained a specified level of development. In other words, the question to which we seek an answer presupposes that we can express age $(y)$ as the dependent with respect to percentage incidence $(x)$ as the independent variable.

Cumulative percentage graphs of the incidence of a qualitative characteristic of puberty derived from the raw data, as in Fig. 1, are of a sigmoid type. For estimation of age in terms of decile incidencelevels, e.g. the age at which exactly 70 per cent. of girls have attained the menarche, we have employed two types of sigmoid curve to fit the data in accordance with the requirements stated in the preceding paragraph: (a) a logistic; (b) a probit, that is, integral normal.

(a) Logistic curves are here defined (on a percentage scale) by the following equation in which $y$, the dependent variable, is the age, and $x$ is the percentage exhibition:

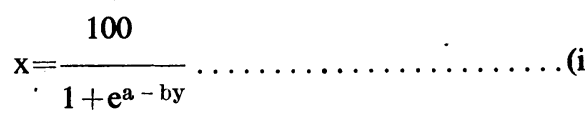

The numerical work of fitting curves of this type to our raw data was carried out by Dr. L. J. Comrie

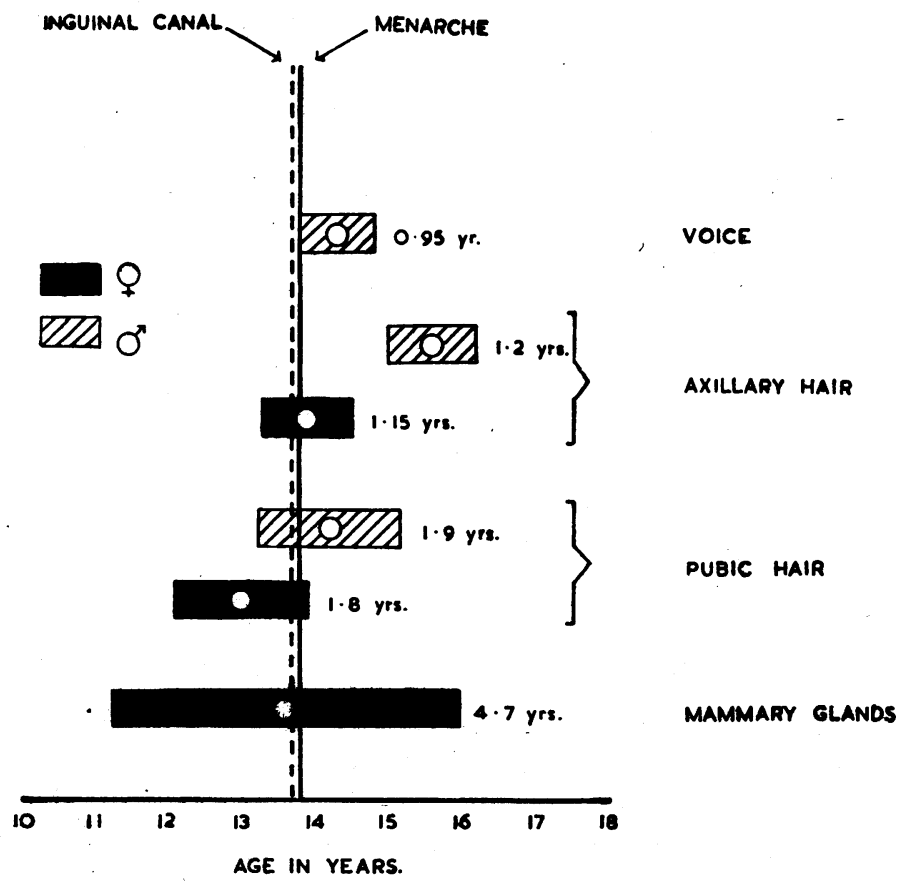

F1o. 4.-Duration and median age of metamorphosis with respect to sexually-differentiated characteristics. and his staff of the Scientific Computing Service. As it stands, the form of (i) is not suitable for least squares calculation of $a$ and $b$. We therefore write:

$$
\begin{aligned}
& \mathrm{e}^{a-b y}=\frac{100-x}{\dot{x}}=x^{\prime} \\
& (a-b y)=\log _{e} x^{\prime}=X
\end{aligned}
$$

We are thus left with a simple linear regression equation whose solution involving $n$, the number of yearly age groups, is:

$$
b=-\frac{n \Sigma X y-\Sigma X \Sigma y}{n \Sigma y^{2}-(\Sigma y)^{2}} ; a=\frac{\Sigma X+b \Sigma y_{0}}{n}
$$

Observations involving 100 per cent. or 0 per cent. values are useless for fitting, since they involve indeterminate equations. For the actual computations of $a$ and $b$, the two subsidiary variables, $x^{\prime}$ and $\mathrm{X}$, are calculated from $\mathrm{x}$, and tabulated. For the reasons stated above, $n$ is never greater than 8 . To obtain the deciles, for which $x=10,20, \ldots \ldots 90$, again $\mathrm{X}^{\prime}$ and $\mathrm{X}$ are tabulated, and the corresponding values of $y$ found from the equation.

(b) The computation of an age distribution with respect to decile development levels by the alternative method was carried out for us by the Mathematics Division of the National Physical Laboratory. The assumption inherent in this method is that we may regard the sigmoid which embodies the raw data as the integral of a normal distribution. From the observed percentage values, $x$, the probits or normal deviates, $Y$, corresponding to these percentages are obtained from probit tables. These values, $Y$, plotted against the values of the independent variable, $y$, should give a straight line if the assumption of normality is correct. Again a regression line is computed, and hence a better approximation obtained. The National Physical Laboratory used this method of successive approximation to obtain maximum likelihood estimates of the mean age, standard deviation, and deciles. Besides giving the decile values for the ages, we are thus able to cite the fiducial limits at $P=0.95$ for the mean, standard deviation, and extreme deciles, as also the criterion of goodness of fit $\chi^{2}$ together with the critical value o $\chi^{2}$ against which it is judged. 
TABLE I

Estimatrd Mrdian Ages with Semi-Interquartile Range (Years)

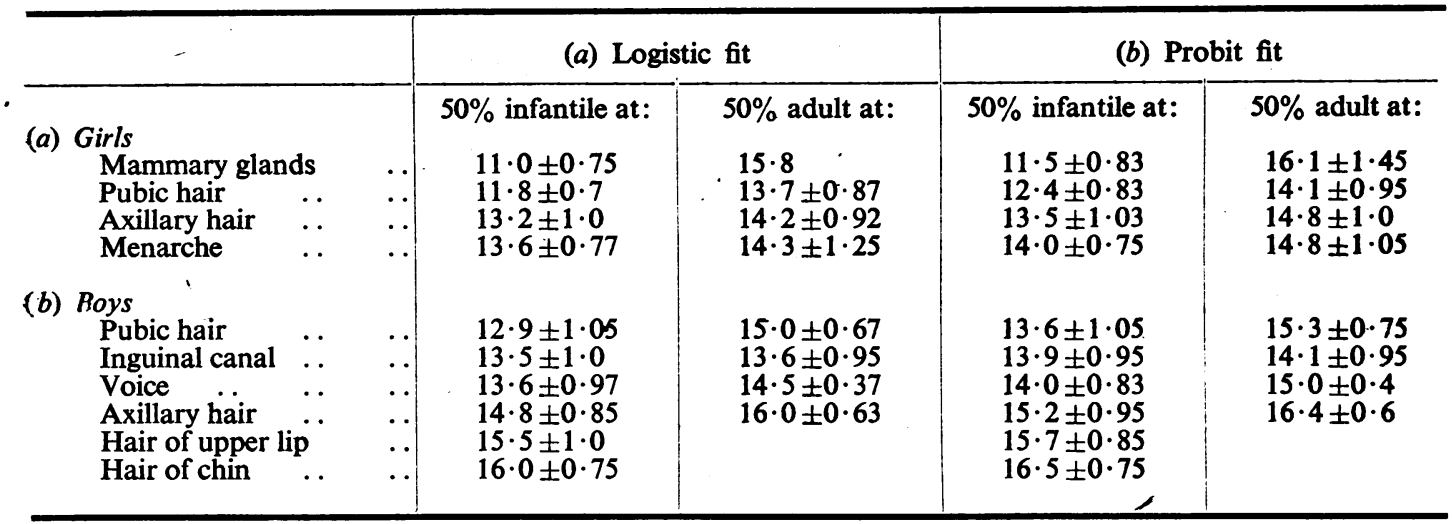

We have reason (see section 5 below) to believe that the logistic formula accords more closely with the trends it describes than does the probit curve, of which the rationale rests on an entirely arbitrary assumption, viz. a normal distribution of the proportion of individuals of a given age grotp attaining a given level of maturity. Though this postulate is attractive from a statistical point of view, it would be difficult to justify on biological grounds.

\section{The Critical Ages}

Each of the attributes specified in Table I admits a distinction between: (i) the infantile condition; (ii) a transitional stage; (iii) the fully-developed or adult state. In defining a mid-point of a gross process on the basis of this split, we may therefore adopt one or both of two criteria: (a) the time at which half the population is still infantile; (b) the time at which half the population is already adult. For example, we may estimate a time at which: (i) 50 per cent. of our sample have no pubic hair and 50 per cent. have an incipient or copious growth; (ii) 50 per cent. of our sample have a copious pubic hair and 50 per cent. have either none or merely a poor growth.

We refer to these two critical ages in Tables I, IV, and VI respectively as the median age at which 50 per cent. are infantile and the median age at which 50 per cent. are adult with respect to a specified characteristic. The corresponding semi-interquartile ranges are bounded by the 25 per cent. and 75 per cent. levels. Needless to say, direct inspection of our data does not permit us to specify either the one or the other. It merely permits us to tabulate the proportions of the three classes in each age group. Such tabulations supply us with the raw data to which it is possible to fit distributions which permit us to treat the percentage of infantile or the percentage of adult types as the independent variable and hence to compute an estimated date at which 10 per cent., 20 per cent., etc., of the total population are still infantile or are already adult with respect to a particular characteristic. Table I sets forth the two critical ages as above defined in accordance with two different methods of interpolation.

Our data record whether girls examined were menstruating regularly or not. If we reject individuals who have not yet menstruated or have done so only once, we may divide those who have attained the menarche into two fairly clear-cut categories from this point of view. Table II shows a threefold age split of this residual sample. Since the proportion of girls with irregular periods diminishes from the menarche onwards, we may infer that an appreciable proportion of all girls pass through a stage of irregular menstruation before attaining regularity; but it would not appear that such a stage invariably follows the menarche. Consequently our data under this heading do not justify a threefold split en rapport with those referring to other phenomena of sexual maturity exhibited in Table $\mathbf{I}$.

TABLE II

INCEPTION OF MENSTRUATION

\begin{tabular}{c|c|c|c}
\hline $\begin{array}{c}\text { Age group } \\
\text { (years) }\end{array}$ & $\begin{array}{c}\text { Period } \\
\text { irregular } \\
\%\end{array}$ & $\begin{array}{c}\text { Period } \\
\text { regular } \\
\%\end{array}$ & Total \\
\hline $12 \frac{1}{2}-14 \frac{1}{2}$ & 25 & 75 & 100 \\
$14 \frac{1}{2}-16 \frac{1}{2}$ & 20 & 80 & 100 \\
\hline
\end{tabular}




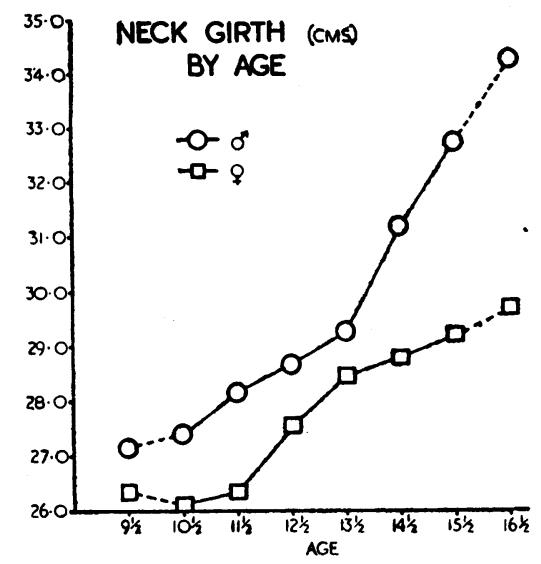

FIG. 5.

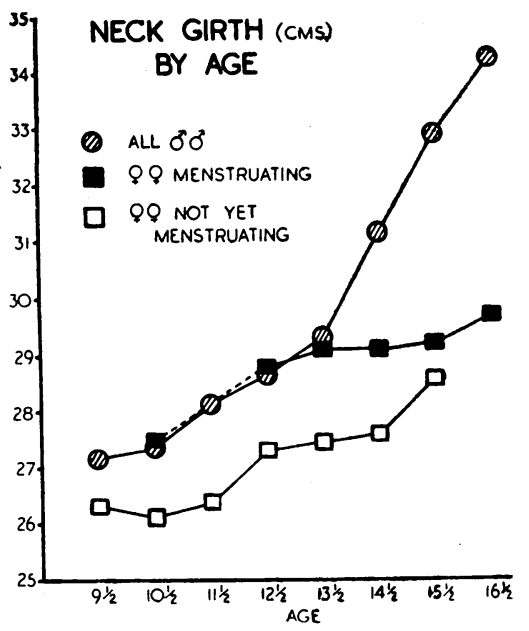

FIG. 6.

\section{Duration of Pubescence}

The critical ages defined in section 4 provide us with signposts of the temporal order of the several phenomena involved in sexual maturation. We now have to ask whether our data can supply us with any information concerning the duration of the manifest processes. It would appear that this is possible with respect to such attributes as are classifiable in three grades specified above, viz. (a) not yet started.(infantile); (b) incipient (maturing); (c) complete (adult). The analogy of a procession marching at uniform speed in single file along an avenue with gates at either end suggests a positive answer.

Individuals specifiable in this context as not yet started are comparable to individuals who have not yet entered the near gate, incipients to those who are

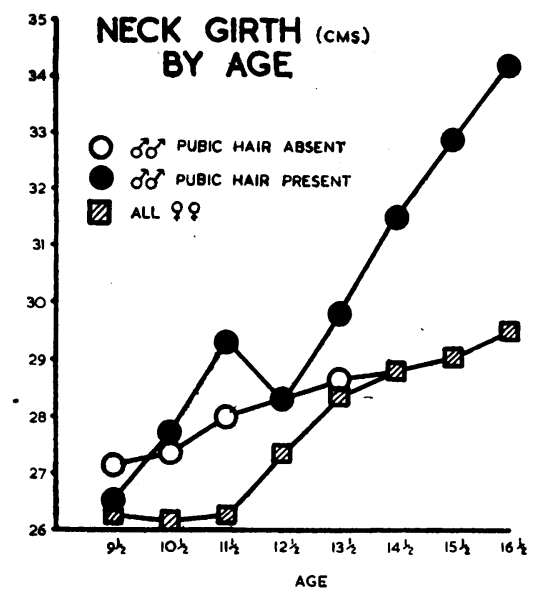

FIG. 7.

TABLE III

Duration of Stages (Years) based on the 50 PeR Cent. LEVEL

\begin{tabular}{|c|c|c|}
\hline$\bullet$ & (a) Logistic fit & (b) Probit fit \\
\hline 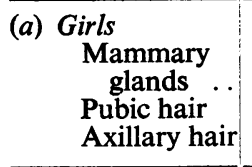 & $\begin{array}{l}4 \cdot 8 \\
1.9 \\
1 \cdot 0\end{array}$ & $\begin{array}{l}4.6 \\
1.7 \\
1.3\end{array}$ \\
\hline $\begin{array}{l}\text { (b) Boys } \\
\text { Pubic hair }\end{array}$ & $2 \cdot 1$ & $1 \cdot 7$ \\
\hline $\begin{array}{l}\text { Inguinal } \\
\text { canal* } \\
\text { Voice } \\
\text { Axillary hair }\end{array}$ & $\begin{array}{l}0.1 \\
0.9 \\
1.2\end{array}$ & $\begin{array}{l}0.2 \\
1.0 \\
1.2\end{array}$ \\
\hline
\end{tabular}

* The figures cited here signify the period which elapses betwecn occlusion of one side and occlusion of the other.

TABLE IIIA

Comparison of Estimates of Duration of Stages (YeARS) Based ON THE LOGISTIC FIr'

\begin{tabular}{|c|c|c|c|}
\hline & $\begin{array}{c}\text { Estimate A } \\
30 \% \text { level }\end{array}$ & $\begin{array}{l}\text { Estimate B } \\
50 \% \text { level }\end{array}$ & $\begin{array}{l}\text { Estimate C } \\
70 \% \text { level }\end{array}$ \\
\hline $\begin{array}{l}\text { (a) Girls } \\
\text { Mammary } \\
\text { glands } \\
\text { Pubic hair } \\
\text { Axillary hair. . }\end{array}$ & $\begin{array}{l}4 \cdot 0 \\
1 \cdot 7 \\
1 \cdot 1\end{array}$ & $\begin{array}{l}4 \cdot 8 \\
1 \cdot 9 \\
1 \cdot 0\end{array}$ & $\begin{array}{r}-\overline{1 \cdot 9} \\
1 \cdot 0\end{array}$ \\
\hline $\begin{array}{ll}\text { (b) Boys } & \\
\text { Pubic hair } \\
\text { Inguinal } \\
\text { canal* } \\
\text { Voice } \\
\text { Axillary hair.. }\end{array}$ & $\begin{array}{l}2 \cdot 4 \\
0 \cdot 2 \\
1 \cdot 1 \\
1 \cdot 3\end{array}$ & $\begin{array}{l}2 \cdot 1 \\
0 \cdot 1 \\
0 \cdot 9 \\
1 \cdot 2\end{array}$ & $\begin{array}{l}1 \cdot 8 \\
0 \cdot 1 \\
0 \cdot 1 \\
1 \cdot 0\end{array}$ \\
\hline
\end{tabular}

* See remarks in footnote to Table III. 
still between the two gates, and the adult class to those who have passed through the far gate. If exactly 50 per cent. of the procession has not yet entered the near gate (Fig. 2) at a time $t_{1}=t_{50}$, and exactly 50 per cent. have passed the far gate at a time $t_{2}=t_{50}+\Delta t_{50}$, the difference $\left(\triangle t_{50}\right)$ is the time taken for an individual to complete the process of passing through the avenue. More generally (Fig. 3) we may suppose that exactly $x$ per cent. have not yet entered the near gate at time $t_{1}=t_{x}$, and that exactly $y$ per cent. have passed out of the far gate at $t_{2}=t_{y}$. The time taken for an individual to complete the course between the two gates is $t_{y}-t_{x}$, if $y=100-x$. The assumption that speed is uniform is, of course, arbitrary and certainly inapplicable to our problem; but the above considerations suggest that $t_{y}-t_{x}$ is a representative estimate of the duration of a manifest transformation of the type under consideration. That is to say, the mean interval involved is the difference between: (a) the age at which exactly $x$ per cent. individuals do not as yet exhibit detectable manifestations of the adult trait; (b) exactly $(100-x)$ per cent. are fully mature.

The threefold split which our data permit with respect to the closure of the inguinal canal, that is, both retractile, right or left only retractile, and neither retractile, do not correspond with the three stages specified above as infantile, maturing, and adult. Accordingly, the time interval specified in Tables III and IIIA with respect to the inguinal canal does not signify the duration of the process of occlusion. What it does signify is the interval between completion of occlusion of the canal on one side and that of occlusion of the inguinal canal on the other side.

Table III shows estimates of duration of stages based on the 50 per cent. level separately in accordance with the logistic formula and the probit formula. Table IIIA, which refers to the logistic method, shows different estimates respectively consistent with taking $x$ as 30 per cent. (A), 50 per cent. (B), and 70 per cent. (C). The three separate estimates derived from the probit fit exhibit a systematic error inasmuch as the B estimate (50 per cent. level) consistently lies between the $\mathrm{A}$ and $\mathrm{C}$ estimates for a given character. On this account we regard the logistic formula as a more satisfactory descriptive device than the alternative specified in paragraph 3 above.

\section{Quantitative Criteria of Sexual Dimorphism}

In the course of examining our data with respect to two outstanding quantitative criteria of sexual dimorphism, namely neck girth and hip width, we computed several indices relating the relevant measurements to growth along other axes. For this purpose we took (inter alia) as our standard of

TABLE IV

Relation of Physique to Median Age (Years)-Girls (with Semi-interquartile Range)

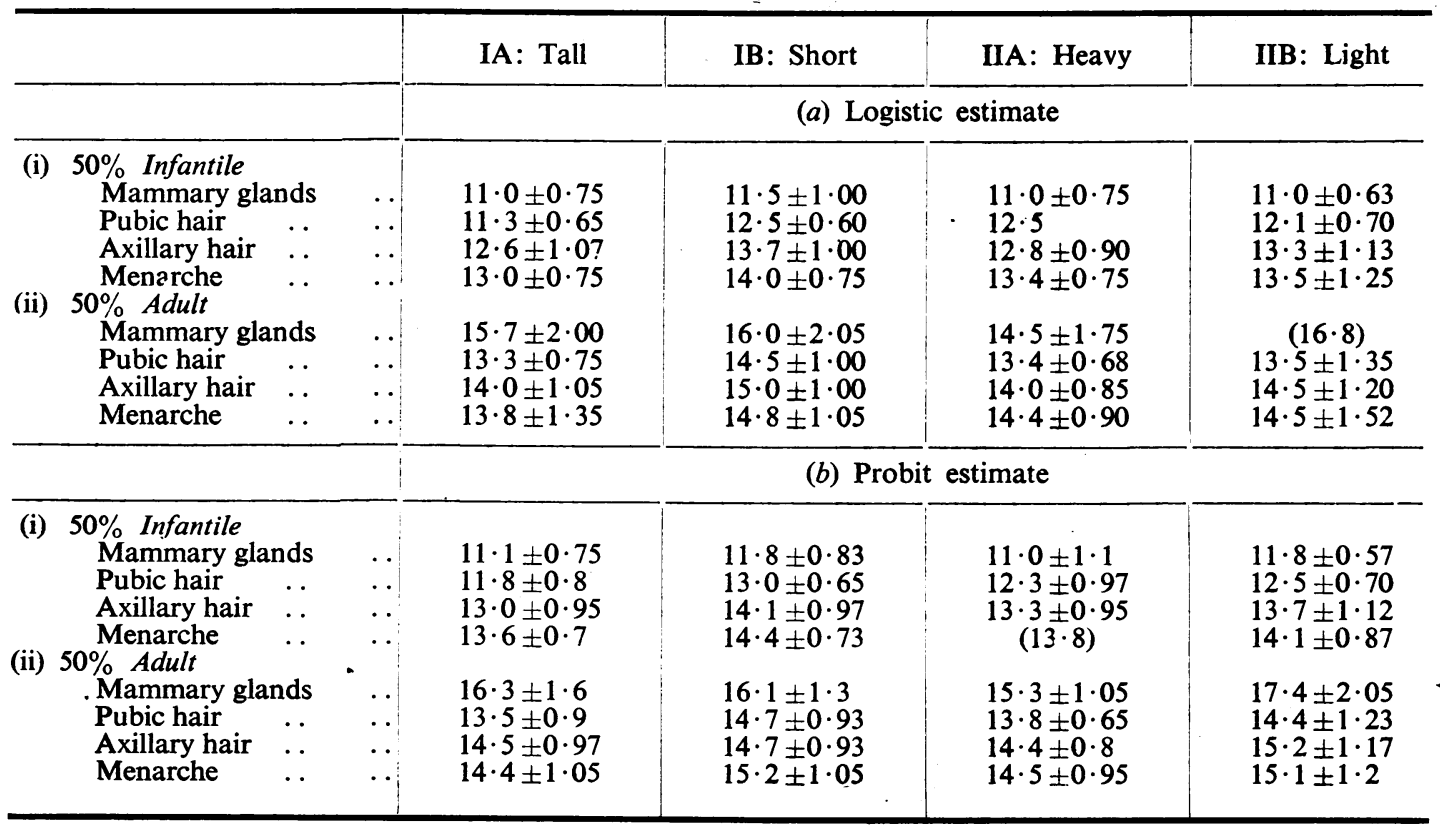


TABLE V

Relation of Physique to Duration (Years) (50 Per CENT. LEVFL)-GIRLS

\begin{tabular}{|c|c|c|c|c|c|}
\hline & & IA & IB & IIA & IIB \\
\hline & & \multicolumn{4}{|c|}{ (a) Logistic estimate } \\
\hline $\begin{array}{l}\text { Mammary glands } \\
\text { Pubic hair } . . \\
\text { Axillary hair } \ldots\end{array}$ & $\begin{array}{l}\cdots \\
\cdots \\
\cdots\end{array}$ & $\begin{array}{l}4 \cdot 7 \\
2 \cdot 0 \\
1 \cdot 4\end{array}$ & $\begin{array}{l}4 \cdot 5 \\
2 \cdot 0 \\
1 \cdot 3\end{array}$ & $\begin{array}{l}3 \cdot 5 \\
0 \cdot 9 \\
1 \cdot 2\end{array}$ & $\begin{array}{l}(6 \cdot 0) \\
1 \cdot 4 \\
1 \cdot 2\end{array}$ \\
\hline Axillary hair .. & & \multicolumn{4}{|c|}{ (b) Probit estimate } \\
\hline $\begin{array}{l}\text { Mammary glands } \\
\text { Pubic hair } . . \\
\text { Axillary hair .. }\end{array}$ & $\begin{array}{l}\cdots \\
\cdots \\
\cdots\end{array}$ & $\begin{array}{l}5 \cdot 2 \\
1 \cdot 7 \\
1 \cdot 5\end{array}$ & $\begin{array}{l}4 \cdot 3 \\
1 \cdot 7 \\
0 \cdot 6\end{array}$ & $\begin{array}{l}4 \cdot 3 \\
1 \cdot 5 \\
1 \cdot 1\end{array}$ & $\begin{array}{l}5 \cdot 6 \\
1 \cdot 9 \\
1 \cdot 5\end{array}$ \\
\hline
\end{tabular}

comparison weight, full height, and trunk length. As regards our immediate objective, these exploratory computations added little or nothing to the picture disclosed by the absolute measurements themselves; but they served to focus attention on a striking difference with respect to growth along the bisacromial axis. In this context we shall therefore confine our attention to direct measurements, deferring for a later communication the analysis of relative growth in terms of axial gradients. The salient differences are as follows:

(a) Neck girth. Within the age range covered by the investigation, the mean neck girth of the male (Fig. 5) is greater than that of the female of the same age, but the growth curves diverge noticeably in the fourteenth year, which signalizes a phase of more active growth of the male neck.

(b) Pelvic width. Until the thirteenth year, there is no consistent difference (Fig. 8) between the mean pelvic hip width of the girls and boys of our sample. Thenceforward, in each age group, the absolute mean of the hip width of the female is greater than that of the male of the same age. This is because the pubescence of the male signalizes the onset of a phase of slower growth with respect to the transverse width of the pelvis.

(c) Bisacromial width. At all ages in the range of this enquiry, the mean absolute shoulder width (Fig. 11) of the girl is greater than that of the male, and there is no sharp divergence associated with

TABLE VI

Relation of Physique to Median Age (Years)-Boys (with Semi-interquartile Ranges)
IA: Tall
IB: Short
IIA: Heavy
IIB : Light

(a) Logistic estimate

(i) $50 \%$ Infantile

$\begin{array}{llll}\text { Pubic hair } \quad \ldots & \ldots & 12 \cdot 5 \pm 1 \cdot 00\end{array}$

Inguinal canal $\ldots . . \quad \ldots \quad 12 \cdot 9 \pm 0.93$

$\begin{array}{llll}\text { Voice } \ldots & \ldots & \ldots & 14 \cdot 0\end{array}$

Axillary hair $\quad \ldots \quad \ldots . \quad 14.5 \pm 0.63$

Hair of upper lip $\quad \ldots \quad 15 \cdot 0 \pm 0.87$

Hair of chin .. .. $16.0 \pm 0.75$

(ii) $50 \%$ Adult

$\begin{array}{llll}\text { Pubic hair } \quad . . & \ldots & 14.5 \pm 0.63\end{array}$

Inguinal canal ,. $\quad \ldots \quad 13 \cdot 1 \pm 0.93$

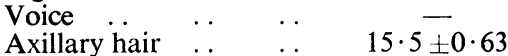

$13 \cdot 4 \pm 1 \cdot 15$
$14 \cdot 1 \pm 1 \cdot 00$
$13 \cdot 5 \pm 1 \cdot 07$
$15 \cdot 5 \pm 1 \cdot 10$
$15 \cdot 5 \pm 0 \cdot 87$
$16 \cdot 5 \pm 0 \cdot 63$
$15 \cdot 5 \pm 0 \cdot 87$
$14 \cdot 3 \pm 0 \cdot 97$
$16 \cdot 5$

$12 \cdot 9 \pm 1 \cdot 20$

$12 \cdot 6 \pm 0 \cdot 73$

$14 \cdot 0$

$14 \cdot 2 \pm 0 \cdot 78$

$14 \cdot 5 \pm 0 \cdot 75$

$15 \cdot 5 \pm 0 \cdot 75$

$14 \cdot 0 \pm 0 \cdot 50$

$12 \cdot 9 \pm 0 \cdot 75$

$15 \cdot \overline{0 \pm 0} \cdot 63$

(b) Probit estimate (i) $50 \%$ Infantile

$\begin{array}{llll}\text { Pubic hair } & \ldots & \ldots & 13 \cdot 2 \pm 1 \cdot 0\end{array}$

Inguinal canal $\ldots \quad \ldots \quad 13 \cdot 5 \pm 0.9$

$\begin{array}{llll}\text { Voice } \ldots & \ldots & \ldots & 13.6 \pm 0.8\end{array}$

Axillary hair $\quad . \quad \ldots \quad 14.7 \pm 0.67$

Hair of upper lip $\quad \ldots \quad 15 \cdot 3 \pm 0.77$

Hair of chin $\quad . \quad \ldots \quad 16 \cdot 2 \pm 0.72$

(ii) $50 \%$ Adult

Pubic hair $\quad \ldots \quad \ldots \quad 14 \cdot 9 \pm 0.57$

Inguinal canal .. $\quad \ldots \quad 13.6 \pm 0.9$

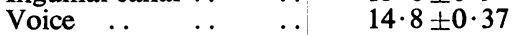

Axillary hair $\quad . \quad$.. $\quad 15 \cdot 9 \pm 0.72$
$14 \cdot 0 \pm 1 \cdot 1$

$14 \cdot 4 \pm 0 \cdot 9$

(14.4)

$15 \cdot 9 \pm 1 \cdot 12$

$16 \cdot 2 \pm 0 \cdot 9$

$16 \cdot 9 \pm 0 \cdot 7$

$15 \cdot 8 \pm 0 \cdot 8$

$14 \cdot 5 \pm 0 \cdot 82$

$15 \cdot 3 \pm 0 \cdot 35$

$17 \cdot 0 \pm 0.92$
$13 \cdot 1 \pm 0 \cdot 92$

$13 \cdot 3 \pm 0 \cdot 82$

$13 \cdot 6 \pm 0 \cdot 75$

$14 \cdot 6 \pm 0 \cdot 75$

$15 \cdot 2 \pm 0 \cdot 72$

$16 \cdot 1 \pm 0 \cdot 27$

$14 \cdot 7 \pm 0 \cdot 5$

$13 \cdot 5 \pm 0 \cdot 8$

$14 \cdot 6 \pm 0.32$

$15 \cdot 8 \pm 0 \cdot 7$
$13 \cdot 5 \pm 1 \cdot 17$

$14 \cdot 2 \pm 1 \cdot 00$

$14 \cdot 0 \pm 1 \cdot 25$

$15 \cdot 5 \pm 0.95$

$16 \cdot 0 \pm 0 \cdot 63$

$16 \cdot 5 \pm 0.63$

$15 \cdot 5 \pm 0 \cdot 75$

$14 \cdot 3 \pm 1 \cdot 05$

$16 \cdot 5$ 
TABLE VII

Relation of Physique to Duration (Years) (50 Per CENT. LEVEL)-BOYS

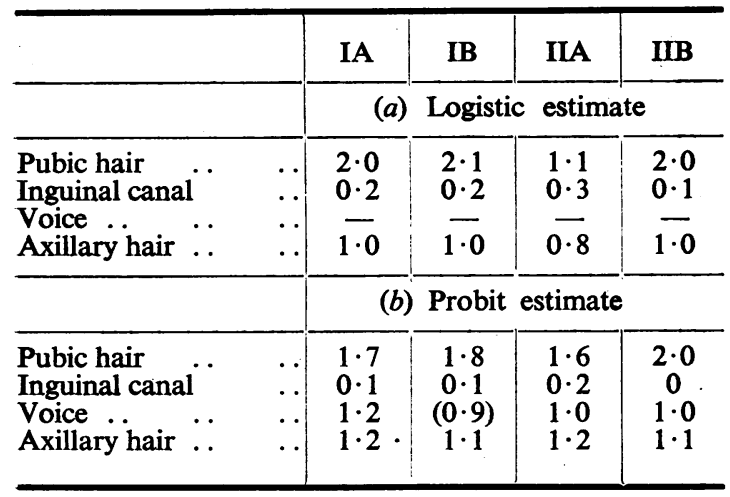

puberty. On the contrary, our data suggest a slight convergence, owing to acceleration of growth among males and retardation among females about the time of the breaking of the voice of the former and of the menarche of the latter.

The foregoing assertions merely bring into sharper focus what is common observation, namely that: (a) enlargement of the neck is characteristic of male sexual development; $(b)$ widening of the pubic region is characteristic of the female. It might seem that a purely morphological study could furnish no information with respect to the nature of the endocrine mechanisms involved; but we can probe further if we pay due regard to indications of endocrine activity supplied by the onset of changes which antedate the differential growth of the two regions under discussion. For instance, we may separate the boys of one and the same age group into those who are respectively infantile and adult with respect to voice. We are then entitled to surmise that the mean activity of the interstitial cells of the testis in the latter exceeds that of the former. Mutatis mutandis, we can make a similar split with respect to the output of the relevant ovarian hormone or hormones of girls of a given age group by separating those who have attained the menarche from those who have not.

Of itself, the mere fact that the growth of an organ enters on a phase of more active growth at puberty while its growth pursues its previous course in the other sex does not prove that such acceleration is the visible sign of the activity of a hormone peculiar to the sex involved. We might equally conceive the process as one which would inevitably occur unless inhibited by a hormone peculiar to the alternate sex. However, it is possible to discriminate between these alternatives by exploiting the distinction stated in the foregoing paragraph. The fact that all boys and all girls do not show at exactly the same age the first visible indications of endocrine activity associated with their respective gonads makes it possible to associate the activity of one or other gonad with a particular type of differential growth.

The accompanying Figures (5-13)* bring this contrast into perspective. Thus a separation of the male population in successive age groups with respect to the condition of the voice or to pubic hair growth does not divide them into groups of which either conforms much more closely than the other to the female pattern of growth with respect to pelvic width (Fig. 10). On the other hand, the separation of the female population into two groups

* The dotted lines connecting the terminal points in these graphs draw attention to the fact that the class samples for the corresponding age groups are small, and the points subject to a large error of sampling.

TABLE VIII

Contour of Pubic HaIr

\begin{tabular}{|c|c|c|c|c|c|}
\hline Age & & $\begin{array}{c}\text { Apical } \\
\%\end{array}$ & $\underset{\%}{\text { Medium }}$ & $\begin{array}{c}\text { Horizontal } \\
\%\end{array}$ & Total \\
\hline$\underset{\substack{14 \\
>16}}{<16}$ & $\cdot$ & $\begin{array}{c}0 \\
16 \cdot 1 \pm 3 \cdot 8 \\
34 \cdot 4 \pm 8 \cdot 4\end{array}$ & $\begin{array}{l}14 \cdot 3 \pm 9 \cdot 34 \\
63 \cdot 4 \pm 5 \cdot 0 \\
34 \cdot 4 \pm 8 \cdot 4\end{array}$ & $\begin{array}{l}85 \cdot 7 \pm 9 \cdot 34 \\
20 \cdot 5 \pm 4 \cdot 2 \\
31 \cdot 2 \pm 8 \cdot 2\end{array}$ & $\begin{array}{l}100 \cdot 0 \\
100 \cdot 0 \\
100 \cdot 0\end{array}$ \\
\hline Total & $\cdots$ & $18 \cdot 6 \pm 3 \cdot 3$ & $51 \cdot 9 \pm 4 \cdot 2$ & $29 \cdot 5 \pm 3 \cdot 9$ & $100 \cdot 0$ \\
\hline $\begin{array}{l}<12 \frac{1}{2} \\
12 \frac{1}{2}-14 \frac{1}{2} \\
>14 \frac{1}{2}\end{array}$ & & $\begin{array}{c}0 \\
1 \cdot 4 \pm 1 \cdot 0 \\
7 \cdot 8 \pm 7 \cdot 1\end{array}$ & $\begin{array}{l}26 \cdot 3 \pm 10 \cdot 0 \\
48 \cdot 6 \pm 4 \cdot 2 \\
45 \cdot 4 \pm 4 \cdot 2\end{array}$ & $\begin{array}{l}73 \cdot 7 \pm 10 \cdot 0 \\
50 \cdot 0 \pm 4 \cdot 2 \\
46 \cdot 8 \pm 4 \cdot 1\end{array}$ & $\begin{array}{l}100 \cdot 0 \\
100 \cdot 0 \\
100 \cdot 0\end{array}$ \\
\hline Total & $\cdots \quad \cdots$ & $4 \cdot 3 \pm 1 \cdot 2$ & $45 \cdot 7 \pm 2 \cdot 9$ & $50.0 \pm 2.9$ & $100 \cdot 0$ \\
\hline
\end{tabular}




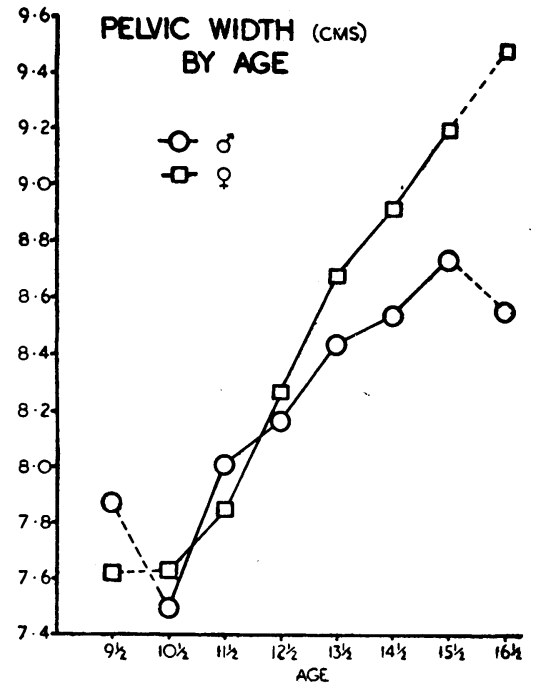

FIG. 8.

(Fig. 9) distinguished by whether they do or do not as yet menstruate isolates a group which conforms to the characteristic female growth pattern from a group which conforms to the male. Whether the testis is or is not active does not appear to be the circumstance relevant to this type of dimorphism. What is decisive is whether the female gonad has come into action. The same method of analysis (Figs. 6 and 7) throws light on the mechanism of differential growth with respect to neck girth. Before the pubic hair appears the male pursues the growth pattern of the female. The accelerated growth with respect to neck girth characteristic of puberty in the male is thus attributable to the activity of the male gonad. As regards bisacromial width, our data are less clear-cut. They suggest that the male and female gonads exercise a contrary influence on the course of growth, indicative of the separate existence of a male growth-promoting and a female growth-retarding hormone.

The conclusion that the male hormone is decisive for neck growth, and that the activity of the female gonads is decisive for the widening of the hips, does not in either case necessarily imply that the hormone involved is sex-specific. We know that castration of the male of henny-feathered poultry breeds (e.g. Campines) induces the assumption of cockfeathering, as does castration of the female of any breed. What would at first appear to be a qualitative distinction between the endocrine activities of the gonads may thus be merely a difference of degree. On this issue our data offer a suggestive clue. With respect to pelvic width, infantile females (Fig. 9)

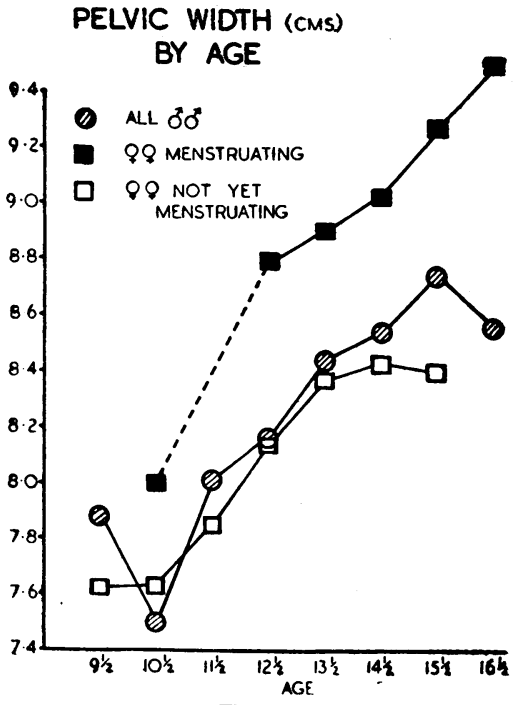

Fig. 9.

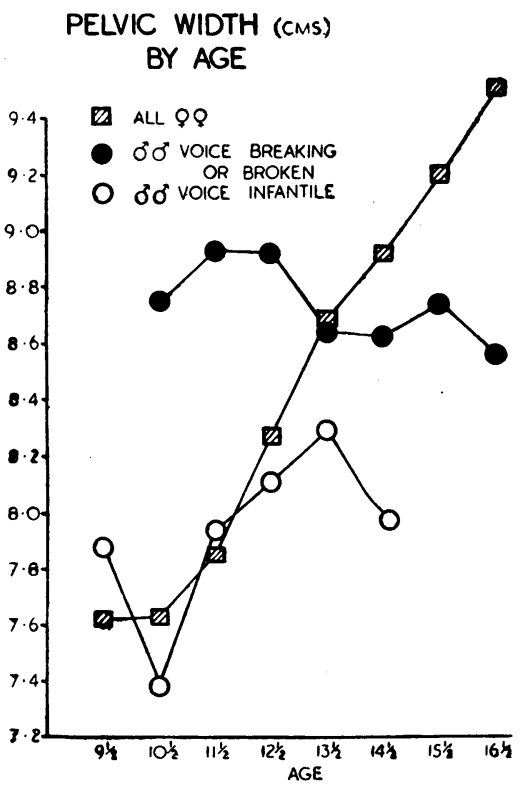

Fig. 10.

appear to be more male than the male. It would beo intemperate to advance either conclusion with ano air of finality. We are content to record the opinion that our data lend colour to the possibility? stated above, that is, what we here call the decisive 0 action of one or other gonad does not necessarilyo signify liberation of a hormone produced by that gonad alone. On the contrary, our data encourage $\vec{\odot}$ the suspicion that the action of one or other gonado 


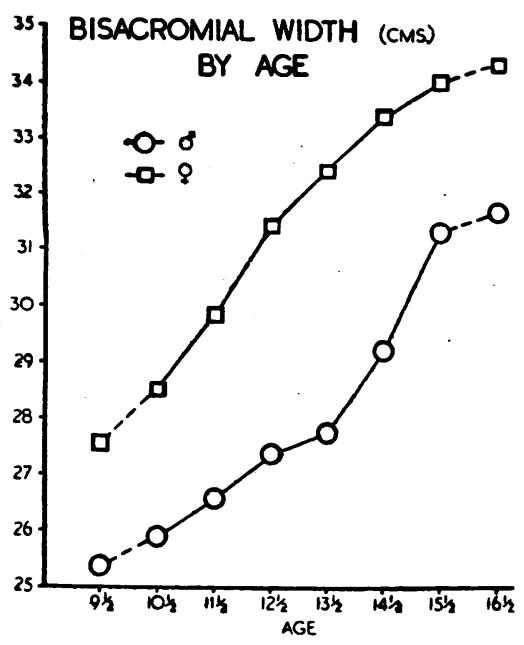

Fig. 11.

is active in a quantitative rather than a qualitative sense.

\section{Relation of Physique to Pubescence}

Whilst it is not our intention to attempt an evaluation of the wider issues involved in the relation between body build and sexual maturation, it is fitting at this stage to record an association which forced itself on our attention at an early stage in the examination of the crude data. The relevant evidence for this association is in Tables IV to VII. For each age group, we have separately calculated the indices exhibited in Tables II and III for each of four classes:

I A and B. The half population with height below the median stature of the same age group; and the half population with height above it;

II $A$ and $B$. The half population weighing less than the median body weight of the same age group; and the half population weighing more.

For each attribute, and for both sexes, the estimated critical age with one notable exception (voice) is conspicuously later for the short than for the tall, and consistently, though less conspicuously, later for the light than for the heavy half of the population. On the other hand, there is no clear indication of an association between the duration of pubescence and stature or body weight. Whether this relation between stature or body weight on the one hand and the critical age, already noticed by Ellis (1946), is a manifestation of a genetical difference associated with body build or an indication of retardation of
BISACROMIAL WIDTH (CMS) BY AGE

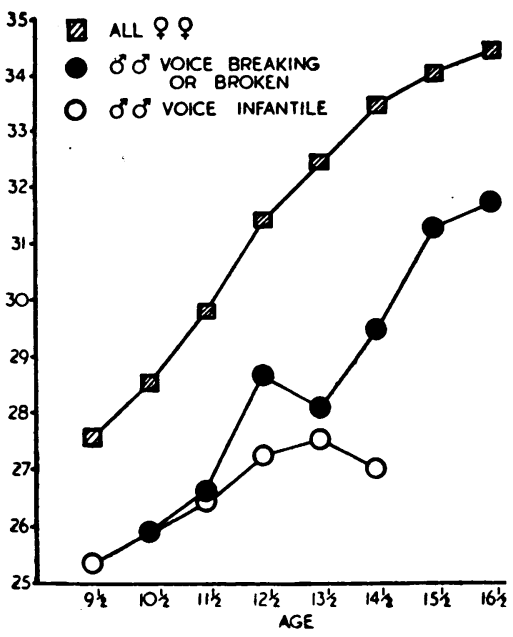

FIG. 12.

BISACROMIAL WIDTH (CMS) BY AGE

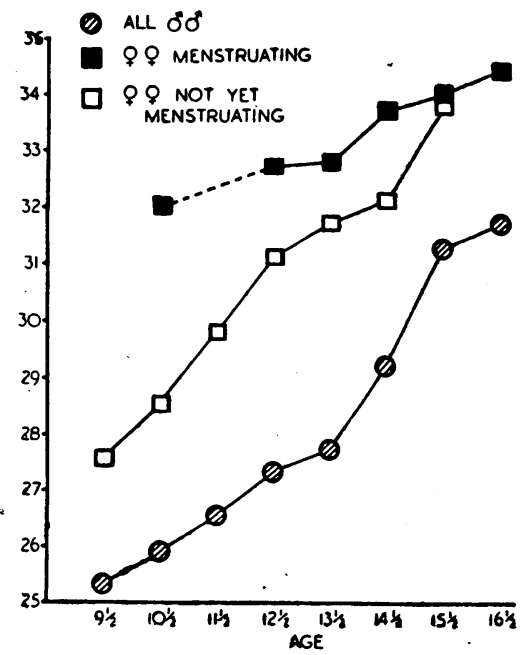

Fig. 13

sexual growth associated with defective nutrition or poor health the data presented in these tables do not permit us to infer. It may indeed be that neither alternative offers a correct explanation of the difference. Acceleration of growth with respect to stature and body weight itself marks the onset of the sexual metamorphosis. Hence a sexually more differentiated sample of one and the same age group will on the whole be taller and heavier than a more infantile sample. By extracting from our total sample the taller and heavier individuals, we are in 
fact extracting a sub-sample with a high proportion of individuals at a more advanced stage of sexual development in each age group. On the other hand, the data of Ellis indicate that boys who reached sexual maturity at an early date within the framework of his investigation had been relatively taller and heavier several years before its onset. In any case, we must agree with Ellis that height and weight norms exhibited without regard to the level of sexual development may be deceptive as standards for growth comparisons.

\section{Contour of the Pubic Hair}

It is a commonplace that the contour of the anterior margin of the pubic hair is characteristic of the sexes, and the descriptive epithets (apical and horizontal) employed in section 2 above are selfexplanatory. For the entire sample of boys and girls with some pubic hair, the analysis of our data yielded the following:

$$
\begin{array}{lllr} 
& & \text { Males (\%) } & \text { Females (\%) } \\
\text { Apical } & \ldots & 18 \cdot 6 \pm 3 \cdot 3 & 4 \cdot 3 \pm 1 \cdot 2 \\
\text { Intermediate } & . . & 51 \cdot 9 \pm 4 \cdot 23 & 45 \cdot 7 \pm 2 \cdot 9 \\
\text { Horizontal } & . & 29 \cdot 5 \pm 3 \cdot 87 & 50 \cdot 0 \pm 2 \cdot 9
\end{array}
$$

These figures do not show such a clear-cut differentiation as one might surmise. A threefold age split shown in Table VIII shows that the horizontal contour is more infantile. Up to the end of our age range the proportion of individuals with pubic hair of the type more characteristic of the fully grown male increases in both sexes.

\section{Summary}

Fig. 4 sufficiently summarizes the salient features concerning median ages of development with respect to axillary hair, pubic hair, voice, mammary glands, and the duration of the process of full development vis-a-vis the median age of the menarche (girls) and the median age of occlusion of the inguinal canal (boys). This figure is based on the mean of estimates obtained by the two methods of curve-fitting set forth in section 3 . Figures 5 to 13 exhibit changes with respect to three axes of growth during the course of development, as set forth in section 6 , where the possible hormonal significance of the differences exhibited is the topic of discussion.

\section{BiBLIOGRAPHY}

Allen, E., et al. (1939). " Sex and Internal Secretions." Williams and Wilkins. Baltimore.

Barker, R. G., and Stone, C. P. (1936). Human Biology, 8, 198 .

Bayer, L. M. (1940). J. Pediat., 17, 345.

Bersamin, R. F., and Gonzales-Bersamin, G. C. (1940). J. Phil. Is. Med.. Ass., 20, 23.

Binet, A. (1938). Paris Méd., $2,470$.

Boas, F. (1930). Science, 72, 44.
Boas, F. (1932). Human Biology, 4, 307.

Bolk, L. (1923). Konin Akad. van Wetenschappen te Amsterdam, Proc. sec. Sci., 26, 650.

Borruat, C. A. (1941). Sem. Med. Buenos Aires, 48, 29.

Bree-Meuleman, L. E. (1940). Geneesk. Tiidschrift (N.E.E.), 80, 163.

Ellis, R. W. B. (1946). Arch. Dis. Childh. 21, 181.

Engle, E. T., and Shelesnyak, M. C. (1934). Human Biology, 6, 431.

Fluhmann, C. F. (1936). Amer. J. Obstet. Gynec., 31, 573.

(1939). “Menstrual Disorders.” W. B. Saunders. Philadelphia.

Gómez, F. D. (1942). Hoia Tisiologica, 2, 25.

Gould, H. N., and Gould, M. R. (1932). J. Amer. Med. Ass., 98, 1349.

Hartman, C. G. (1931). Science, 74, 226.

(1939). Endocrinol., 25, 670.

Henckel, K. O. (1940). Rev. med. Lat. Amer., $26,14$.

Howe, K. (1939). Münsch. med. Wschr., 86, 1113.

Ito, P. K. (1942). Human Biology, 14, 279.

Jones, H. E. (1947). Ibid., 19, 12.

Kark, E. (1943). S. Afr. J. med. Sci., 8, 35.

Kennedy, W. (1933). Brit. J. Obstet. Gynec., 40, 792.

Klineberg, O. (1935). " Race Differences.", Harper Bros. New York.

Lenner, A. (1944). Acta obstet. gynec. scand., $24,229$.

Lipschutz, A. (1924). "The Internal Secretions of the Sex Glands." Heffer, Cambridge.

Marshall, F. H. A. (1922). "The Physiology of Repro- " duction." Longmans and Co. London.

Michelson, N. (1944). Amer. J. Phys. Anthrop., 2, 151.

Mills, C. A. (1937). Human Biology, 9, 43. (1939). Science, 89, 11.

(1941a). Human Biology, 13, 363.

(1941b). Ibid., 13, 378.

(1944). "Climate Makes the Man." Gollancz. London.

and Chenoweth, L. B. (1938). Human Biology, $10,547$.

Priesel, R., and Wagner, R. (1931): Z. Konstitutionslehre, 15, 333.

Pryor, H. B. (1936). J. Pediat., 8, 52.

Riddle, O. (1931). Physiol. Rev., 11, 63.

Robson, J. M. (1940). "Recent Advances in Sex and Reproductive Physiology." Churchill. London.

Schonfeld, W. A. (1943). J. Amer. med. Ass., 121, 177.

Schultz, A. H. (1940). Contr. Embryol. Carnegie Inst., $28,1$. (1941). Ibid., 29, 57.

Shock, N. W. (1941). Am. J. Physiol., 133, 610. (1942). Am. J. Dis. Child., 64, 19. (1943). Am. J. Physiol., 139, 288.

- (1946). Texas Reports Biol. Med., 4, 3, 289, 368. Simmons, K., and Greulich, W. W. (1943). J. Pediat.,

22, 518. $9,1$.

Wissler, H. (1943). Schweiz. med. Wschr., 73, 409.

Yerkes, R. M. (1943). "Chimpanzees: A Laboratory Colony." Yale University Press.

, and Yerkes, A. (1929). "The Great Apes: a Ștudy of Anthropoid Life." Yale University Press.

Zuckerman, S. (1930). Proc. zool. Soc. Lond., $2,691$. (1932). "The Social Life of Monkeys and Apes." Kegan Paul. London. (1937). Proc. zool. Soc. A. Lond., 107, 315. van Wagenen, G., and Gardiner, R. H. (1938). Ibid., 108, 385. 